\title{
Current approaches to the treatment of Parkinson's disease
}

\author{
Joseph Jankovic \\ L Giselle Aguilar \\ Parkinson's Disease Center and \\ Movement Disorders Clinic, \\ Department of Neurology, Baylor \\ College of Medicine
}

Correspondence: Joseph Jankovic Parkinson's Disease Center and

Movement Disorders Clinic, Department of Neurology, Baylor College of Medicine, 6550 Fannin, Suite 180I, Houston, Texas 77030, USA

Tel +I 7/37985998

Fax +I 7I3 7986808

Email josephj@bcm.tmc.edu

\begin{abstract}
Enormous progress has been made in the treatment of Parkinson's disease (PD). As a result of advances in experimental therapeutics, many promising therapies for PD are emerging. Levodopa remains the most potent drug for controlling PD symptoms, yet is associated with significant complications such as the "wearing off" effect, levodopa-induced dyskinesias and other motor complications. Catechol-o-methyl-transferase inhibitors, dopamine agonists and nondopaminergic therapy are alternative modalities in the management of PD and may be used concomitantly with levodopa or one another. The neurosurgical treatment, focusing on deep brain stimulation, is reviewed briefly. Although this review has attempted to highlight the most recent advances in the treatment of PD, it is important to note that new treatments are not necessarily better than the established conventional therapy and that the treatment options must be individualized and tailored to the needs of each individual patient.
\end{abstract}

Keywords: Parkinson's disease, levodopa, medical treatment, pallidotomy, deep brain stimulation

\section{Medical treatment of Parkinson's disease}

Enormous progress has been made in the treatment of Parkinson's disease (PD) over the past half century, but levodopa remains the most potent drug for controlling PD symptoms (Jankovic 2008a). Prior to instituting medical therapy, a correct diagnosis of PD must be established and the level of impairment (motor, sensory, autonomic and mental) determined (Table 1). Each patient's therapy is to be individualized, and diverse drugs other than levodopa are presently available. Among these are the dopamine agonists (DA), catechol-o-methyl-transferase (COMT) inhibitors and nondopaminergic agents (Figure 1). Head-to-head comparisons of drugs within classes are rare, and the differences that have emerged are related to the effects on motor fluctuations, dyskinesias, on/off times and adverse effects of the specific agents within each class (Jankovic and Stacy 2007).

\section{Levodopa}

Levodopa is the most potent drug for controlling PD symptoms, particularly those related to bradykinesia (Jankovic 2002a). However, because levodopa therapy is frequently associated with motor complications, such as fluctuations and dyskinesias, there is ongoing debate as to when in the course of PD it is most appropriate to initiate levodopa therapy (Stern 2004; Weiner 2004). The addition of carbidopa, a peripheral dopa decarboxylase inhibitor, enhances the therapeutic benefits of levodopa. In patients who are particularly sensitive to peripheral side effects such as nausea and vomiting, additional carbidopa $\left(\right.$ Lodosyn $^{\circledR}$ ) may be added to the conventional carbidopa/levodopa preparation.

A majority of patients treated with levodopa experience motor fluctuations, dyskinesias or other complications after 5 years of treatment (Jankovic 2005). Since motor fluctuations and dyskinesias are primarily related to the dose and duration of levodopa treatment (Schrag and Quinn 2000), most parkinsologists advocate 
Table I Guidelines for treatment of Parkinson's disease

\section{Ensure correct diagnosis}

Determine level of motor, mental, sensory, autonomic and other impairments

Educate the patient about the disease and importance of mental and motor activity

Consider putative neuroprotective agent(s)

Select the most appropriate symptomatic therapy, targeted to the most troublesome symptoms

Consider surgery (DBS) in patients who are levodopa-responsive but their levodopa-related motor complications cannot be managed adequately with medication adjustments

Therapy must be customized and tailored to the individual needs of the patient

Abbreviation: DBS, deep brain stimulation.

therapeutic strategies designed to delay the onset of levodopa therapy in order to delay the onset of levodopa-related motor complications (Jankovic 2002b).

The reported frequency of motor complications between the different studies varies, partly because of differences in definitions of the thresholds for recognizing motor complications (Marras and Lang 2003). One of the most common problems in patients taking levodopa is delayed onset of response after ingesting a dose of levodopa. A delay in achieving "on" state or a total response failure accounted for more than $60 \%$ of daily "off” time among 327 patients with advanced PD (Blindauer et al 2003).

There are different types of levodopa-induced dyskinesias, such as the "peak-dose dyskinesias", "biphasic dyskinesias" and "wearing-off" dyskinesias (Fahn 2000; Jankovic 2002a). Besides cumulative dose and duration of levodopa treatment, there are other risk factors that should be considered before initiating levodopa therapy. Young-onset PD patients seem particularly likely to develop levodopa-induced dyskinesias. Certain genetic forms of PD, such as PARK2 and PARK8 have been associated with a higher risk of levodopa-related motor complications (Lucking et al 2000; Schrag and Schott 2006).

There are three strategies designed to improve levodopainduced dyskinesias: 1) reduce the dosage of levodopa, 2) use drugs known to ameliorate dyskinesias, and 3) surgery. Several drugs, including amantadine, have been reported to improve levodopa-induced dyskinesias without necessitating the reduction in levodopa dosage (Verhagen Metman et al 1999). The addition of a COMT inhibitor, MAO-I inhibitor or a dopamine agonist inhibitor may be used in the management of levodopa-induced motor complications (Jankovic et al 2007) (Table 2). Other drugs with antidyskinetic effect include clozapine, fluoxetine, propranolol, the cannabinoid

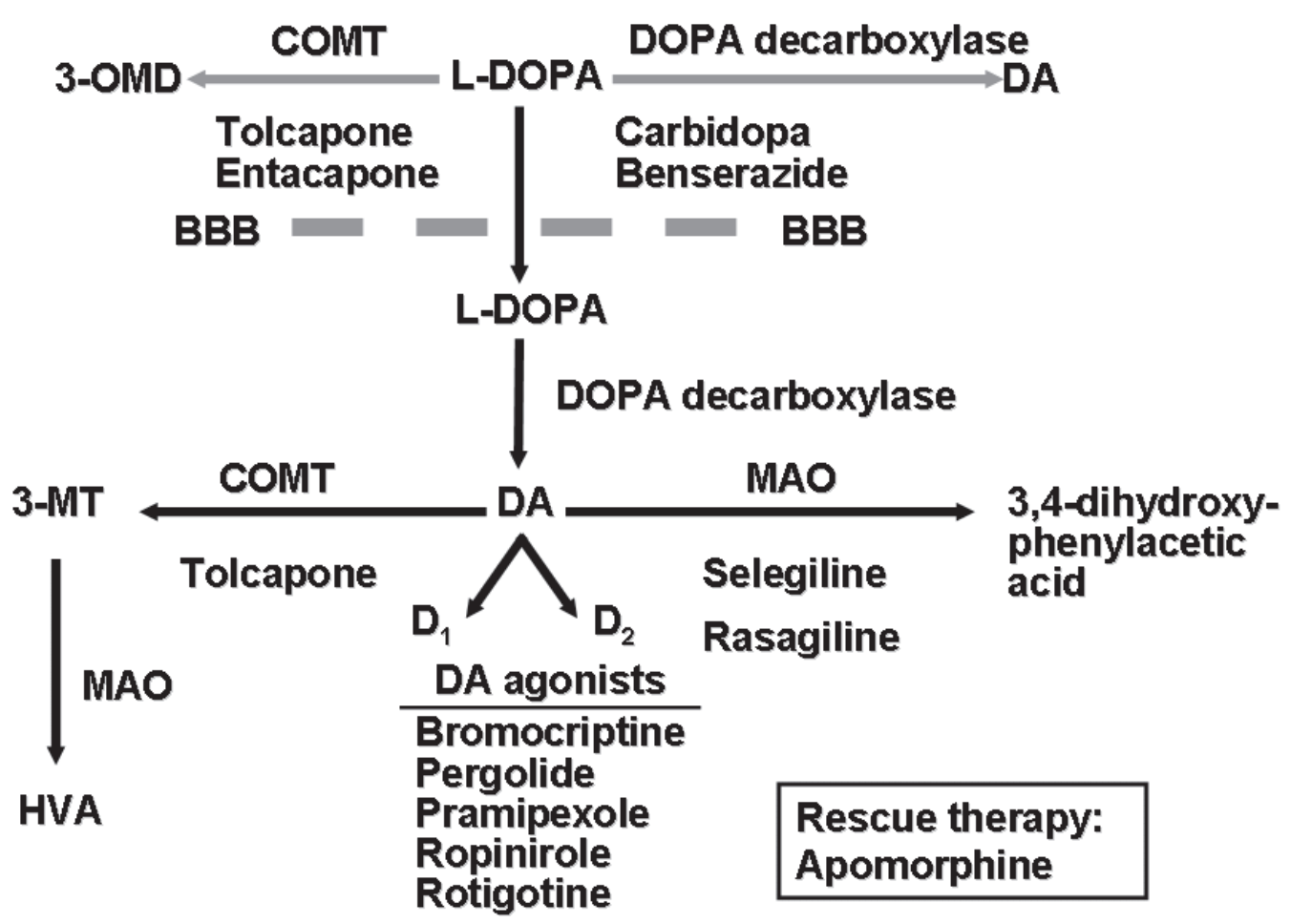

Figure I Pharmacologic treatment options available for PD.

Abbreviations: BBB, blood-brain barrier; COMT, catechol-O-methyl-transferase; DA, dopamine; L-DOPA, 3,4 dihydroxy-L-phenylamine; HVA, homovanillic acid; 3-MT, 3-methoxytramine; MAO, monoamine oxidase. 
receptor agonist nabilone, and fipamezole. Some of the new antiepileptic drugs are being investigated as potential therapies for levodopa-induced dyskinesias. For example, levetiracetam $\left(\right.$ Keppra $^{\circledR}$ ) was found to significantly reduce levodopa-induced dyskinesias in MPTP-lesioned marmosets (Hill et al 2003). In patients with severe motor fluctuations, apomorphine, a subcutaneous dopamine agonist, may be used as rescue therapy (Pietz et al 1998).

The "wearing off" effect, the most frequent form of motor fluctuation, appears to be related to the shortening of levodopa's half-life in the striatum as a result of impaired capacity to store and buffer the striatal concentration of levodopa, due to a loss of striatal dopaminergic terminals (Verhagen Metman et al 2000). Amantadine, a NMDA receptor blocker, has been found to ameliorate motor fluctuations in parkinsonian animals and patients (Verhagen Metman et al 2000; Pereira et al 2005). In patients with "wearing-off" and "on-off" phenomena, the response to apomorphine, a postsynaptically acting dopamine agonist, is shortest and steepest in patients with the most severe motor fluctuations (Manson et al 2002). In addition, apomorphine is capable of sustaining a long-duration response (Nutt and Carter 2000).

Strategies designed to prolong and smooth out the therapeutic concentrations of levodopa-related motor fluctuations usually improve by increasing the frequency of administration of levodopa. Slow-release preparations of levodopa, such as Sinemet ${ }^{\circledR}$ CR, offer the possibility of "smoothing out" clinical fluctuations by slowly releasing the levodopa from a special matrix. In addition to prolonging the "on" time, smoothing out the wearing off response and reducing the total number of doses and tablets taken per day, Sinemet $\mathrm{CR}$ also seems helpful in alleviating troublesome nighttime rigidity, thus allowing patients to have more restful nights and better nighttime mobility. Potential disadvantages of Sinemet CR over standard preparations include delayed or poor response after the morning dose (absence of the "morning kick") and an exacerbation and prolongation of peak-dose dyskinesias.

Continuous dopaminergic stimulation (CDS) has been advocated as a strategy to prevent or control levodoparelated motor fluctuations presumably associated with pulsatile stimulation associated with levodopa dosing, although this concept has been challenged (Nutt 2007). CDS methods include duodenal infusions of levodopa, oral solutions of levodopa made by dissolving it with ascorbic acid in water, a dispersible form of levodopa (Etilevodopa ${ }^{\circledR}$ ), subcutaneous or intramuscular injections of levodopa ethylester, and intravenous (and intraventricular) administration
Table 2 Antidyskinesia drugs

Amantadine (NMDA inhibitor)

Buspirone (G-HTIA agonist)

Fluoxetine (SSRI)

Propranolol

Clozapine (D4/DI antagonist, 5-HT2 antagonist)

Olanzapine (DI/D2/D4 antagonist)

Naloxone (opioid antagonist)

Nabilone (cannabinoid receptor agonist)

Sarizotan (D4 and 5HT ${ }_{1 \mathrm{~A}}$ agonist)

Istradefylline ( $K W-6002$, adenosine $A_{2 A}$ antagonist)

Fipamezole (JP-1730, alpha-adrenergic antagonist)

Levetiracetam (Keppra $\left.{ }^{\circledR}\right)$

Talampanel (AMPA antagonist)

Idazoxan (alpha-2 antagonist)

of levodopa methyl ester, but the latter methods are not practical and have not translated into clinical practice (Stocchi et al 2005).

\section{COMT inhibitors}

Another strategy to prolong DA response utilizes the inhibition of COMT by drugs such as entacapone $\left(\right.$ Comtan $\left.^{\circledR}\right)$. Entacapone, because of its short half-life, requires frequent administration (200 mg, up to 8 times per day); most patients take entacapone with each dose of levodopa (Schrag 2005). Tolcapone $\left(\right.$ Tasmar $\left.^{\circledR}\right)$, another COMT inhibitor, is rarely used because of a report of three cases of acute fulminant liver failure (Assal et al 1998; Olanow et al 2000) leading to black box warning and intensive monitoring requirements (Ellison 1998). The safety and tolerability of adjunctive tolcapone initiated simultaneously with levodopa was recently evaluated, with a focus on changes in liver transaminases and potential hepatotoxicity (Lees et al 2007). In this study, 677 levodopanaive patients in early stages PD were randomized to receive placebo or tolcapone $100 \mathrm{mg}$ three times daily, added to standard doses of levodopa plus carbidopa or benserazide. In both placebo and tolcapone treated patients, there were mild elevations in transaminase levels, less than 3 times the upper limit of normal (ULN), whereas potentially serious increases of up to or over 3 times the ULN were infrequent $(1.8 \%$ in the tolcapone treated group compared to $1.2 \%$ in those treated with placebo, $p=0.5$ ), supporting the safe use of tolcapone in selected patients who are monitored for potential liver toxicity. According to current FDA recommendations (1998), the monitoring should include serum alanine aminotransferase (ALT) and aspartate aminotransferase (AST), prior to starting treatment with tolcapone. These enzymes should be monitored every two weeks for the first year, every 4 weeks for the next 6 months and then every 
8 weeks thereafter. Prior to increasing tolcapone, ALT and AST levels should be monitored and subsequently scheduled at the above mentioned frequency.

Theoretically, the COMT inhibitors have an advantage over Sinemet CR in that they do not delay the absorption of levodopa and, although they increase the levodopa plasma concentration, they do not increase the time to reach the peak concentration or the maximal concentration of levodopa (Ruottinen and Rinne 1998). While this pharmacologic action of the COMT inhibitors may prolong the "on" time without markedly increasing dyskinesias, most studies do report increased levodopa-induced dyskinesia in patients taking COMT inhibitors, requiring a substantial $(>25 \%)$ reduction in daily levodopa dosage. Thus patients, with and without fluctuations, benefit from the addition of entacapone to their levodopa treatment. Except for nausea and increased dyskinesia, entacapone is usually well tolerated. Early intervention, such as phone calls to the patients, clearly improves compliance, and this translates into not only increased "on"-time and reduced levodopa dosage, but also further improvement in quality of life measures (Grandas et al 2007).

In 2003, the US FDA approved triple combination tablets $\left(\right.$ Stalevo $\left.{ }^{\circledR}\right)$ containing carbidopa, levodopa, and entacapone for end-of-dose wearing off. In a randomized, crossover study of 132 healthy subjects, the levodopa AUC (area under the curve) was essentially the same when used in the triple combination versus when administered separately, indicating equivalent pharmacokinetics (Heikkinen et al 2003; Hauser 2004).

\section{Dopamine agonists}

The possibility that levodopa is neurotoxic, and that the onset of levodopa-induced complications may be related to the duration of treatment, are the two most important reasons why many experts recommend delaying levodopa therapy until parkinsonian symptoms clearly begin to interfere with patients' functioning and normal lifestyle. In order to delay or prevent levodopa-induced complications many parkinsonologists recommend using DA agonists as the initial or early form of dopaminergic therapy (Jankovic 2000). When used as monotherapy, DA agonists provide only modest improvement in parkinsonian symptoms, but the improvement may be sufficient to delay the introduction of levodopa by several months or years.

Dopamine agonists (DA) exert their pharmacologic effect by directly activating DA receptors, bypassing the presynaptic synthesis of DA. Experimental and clinical studies have provided evidence that activation of the
D2 receptors is important in mediating the beneficial antiparkinsonian effects of DA agonists, but concurrent D1 and D2 stimulation is required to produce optimal physiological and behavioral effects (Brooks 2000) (Table 3). In contrast to the traditional DA agonists (bromocriptine and pergolide), pramipexole and ropinirole are nonergolines and therefore are expected to have a lower risk of complications such as peptic ulcer disease, vasoconstrictive effects, erythromelalgia, pulmonary and retroperitoneal fibrosis, and valvular heart disease (Tintner et al 2005; Roth 2007; Zanettini et al 2007). Pramipexole often causes dose-dependent and idiosyncratic peripheral edema (Tan and Ondo 2000). Because of the potential for valvular heart disease, the ergot dopamine agonists have been essentially discontinued from medical practice.

Pramipexole has been shown to be a safe and effective drug when used as monotherapy in early stages of PD (Parkinson Study Group 2002) and in mild to moderate PD (Weiner et al 2001). In addition to its beneficial effects on the PD clinical symptoms and levodopa sparing (about $25 \%$ reduction in daily levodopa dosage), pramipexole has been demonstrated to possibly exert a neuroprotective effect and to enhance neurotrophic activity in mesencephalic dopaminergic cultures (Zou et al 1999).

Ropinirole has been also demonstrated to be effective in early PD (Korczyn et al 1999; Rascol et al 2000). In clinical practice, dosages high as $24 \mathrm{mg}$ may be needed to achieve optimal response (Korczyn et al 2002). Some studies have shown that dosages of ropinirole as high as $35 \mathrm{mg}$ per day are safe and provide additional benefits in patients with advanced PD (Cristina et al 2003). In addition to increasing dosages of DA agonists, several studies have explored the potential for synergistic effects of combined DA agonist therapy. For example, Stocchi et al (2003) found in an open label study that the addition of cabergoline to other DA agonists significantly improved the UPDRS scores and motor fluctuations and that dual DA agonist therapy may be useful in patients with PD with or without levodopa.

Meta-analysis comparing adverse effects of ropinirole to pramipexole showed that there was no significant difference in the risk of dizziness, nausea, or hypotension with either drug individually or in combination when compared with levodopa (Etminan et al 2003). The use of ropinirole appeared to be associated with a higher risk of hypotension and somnolence as compared with pramipexole when compared with placebo and the use of pramipexole appeared to be associated with a higher risk of hallucinations than use of ropinirole when compared with placebo. 
Table 3 Pharmacology of dopamine agonists

\begin{tabular}{llllll}
\hline Parameter & $\begin{array}{l}\text { Bromocriptine } \\
\text { parlodel }\end{array}$ & $\begin{array}{l}\text { Pergolide } \\
\text { permax }\end{array}$ & $\begin{array}{l}\text { Ropinirole } \\
\text { requip }\end{array}$ & $\begin{array}{l}\text { Pramipexole } \\
\text { mirapex }\end{array}$ & $\begin{array}{l}\text { Rotogotine } \\
\text { neupro }\end{array}$ \\
\hline DA receptors & D2 > D3 & D3 > D2 > DI & D3 > D2 & D3 > D2 & D3 > D2 > DI \\
Structure & Ergot & Ergot & Nonergot & Nonergot & Nonergot \\
T 1/2 (hours) & $3-8$ & 27 & 7 & 13 & 6.8 \\
Protein binding (\%) & 95 & 90 & 30 & 20 & 92 \\
Liver metabolism & + & + & + & - & + \\
\hline
\end{tabular}

Apomorphine is a water soluble DA and is consequently suitable for intravenous, subcutaneous, sublingual, or intranasal administration (Ondo et al 1999a; Poewe and Wenning 2000). Subcutaneous injections or continuous infusions have been found useful even in advanced PD by reducing the "off" time without necessarily increasing dyskinesias (Pietz et al 1998). In our study of sublingual apomorphine in patients with advanced PD, we found a marked reduction in the UPDRS score, an increase in "on" time, an increase in tapping speed, and a significant reduction in levodopa dosage (Ondo et al 1999b). Several reports have also suggested that apomorphine may exert a neuroprotective effect in MPTP animals and other models (Grünblatt et al 1999). A formulation of a novel highly selective D2 DA agonist, rotigotine, in a silicone based transdermal system $(4.5-18 \mathrm{mg} / \mathrm{patch})$ approved by the FDA in 2007 for the treatment of early PD (Jankovic et al 2007; Watts et al 2007), has also been found to be effective in the treatment of advanced PD (LeWitt et al 2007). The improvement in the UPDRS appears to be dose-dependent, and the drug was well tolerated at plasma levels that produce clinical improvement at doses of 8.4 to $67 \mathrm{mg}$, except for some side effects usually associated with DA agonists, such as somnolence, nausea, vomiting, and occasional skin irritation (Parkinson Study Group 2003; Poewe and Leussi 2005). Rotigotine $\left(\mathrm{Neupro}^{\circledR}\right)$ is available as $2 \mathrm{mg}, 4 \mathrm{mg}$, and $6 \mathrm{mg}$ per day patches. In March 2008, Schwarz Pharma, the German pharmaceutical company who developed the drug, now marketed by UCB Pharma, announced their decision to withdraw the drug from the US market due to formation of crystals in the patches, which interferes with the absorption of the drug into the skin. The company is currently working diligently to correct the problem and is consulting with the FDA to make sure that future supplies meet the highest quality standards.

Although levodopa is clearly the most effective drug for the treatment of motor symptoms of PD, whether levodopa should be used in early stages of PD or delayed until later in the disease process has been the subject of many debates. This debate is partly fueled by the observation that in patients with early onset PD (particularly before the age of 40), their disease course is longer and they have a particularly high risk for developing motor fluctuations and dyskinesias. The argument to delay levodopa therapy is chiefly supported by studies showing that early use of dopamine agonists delays the need for levodopa and thus delays the onset of levodopa-related motor complications, particularly motor fluctuations and dyskinesias, and that dopamine agonists may exert favorable disease-modifying effects (Le and Jankovic 2001; Parkinson Study Group 2002; Simpkins and Jankovic 2003; Whone et al 2003). The strategy of early initiation of levodopa is supported by studies that indicate that levodopa provides a longer period of superior motor control, slower progression of disability, longer life expectancy (Lees et al 2001; Rajput et al 2002), and no difference in "clinically relevant" dyskinesias between levodopa and dopamine agonist treated patients (Lees et al 2001). There is a lower incidence of hallucinations, vomiting, and leg edema with levodopa as compared to dopamine agonists (Whone et al 2003), and no in vivo evidence of levodopa toxicity (Le and Jankovic 2001). Since younger patients seem to be at a higher risk of levodopa-related motor complications, delaying levodopa therapy seems to be a prudent practice at least in this population of PD patients.

\section{Nondopaminergic therapy}

In addition to the dopaminergic drugs, nondopaminergic drugs, such as the anticholinergics and amantadine, may provide satisfactory symptomatic relief in early phases of anti-PD therapy. The anticholinergic drugs, such as trihexyphenidyl or benztropine, are particularly useful in younger patients who are primarily bothered by tremor. Although quite effective, their usefulness is limited by the anticholinergic side effects such as cognitive impairment, dry mouth and urinary symptoms. The tricyclics are often used not only because of their antidepressant effects, but also because of their anticholinergic properties. Mirtazapine $\left(\right.$ Remeron $\left.^{\circledR}\right)$, a novel antidepressant that enhances noradrenergic and serotonergic transmission and acts as a presynaptic alpha-2, 5HT2, and 5HT3 receptor antagonist, has been reported to improve 
rest tremor and levodopa-induced dyskinesia (Pact and Giduz 1999). Istradefylline, a novel adenosine antagonist, has been also reported to provide modest benefit in PD patients with levodopa-related motor complications (Jankovic 2008b). Rapid eye movement (REM) sleep behavior disorder (RBD), which may be the initial manifestations of Parkinsonism, may respond to night-time clonazepam. Drooling (sialorrhea), one of the most embarrassing symptoms of PD caused by impaired swallowing, has been successfully treated with botulinum toxin injections (Bhatia et al 1999; Pal et al 1999; Sheffield and Jankovic 2007).

The most important principle in the management of PD is to individualize therapy and to target the most disabling symptoms. The selected therapy should be based on scientific rationale and designed not only to control symptoms, but also to slow the progression of the disease (Figure 2). Since younger patients are likely to require dopaminergic therapy for longer time and are at increased risk for the development of levodopa complications, levodopa sparing strategies, such as the use of MAO inhibitors and DA agonists, are even more critical in this population (Jankovic 2000). Certain symptoms of PD, such as dysarthria, dysphagia, freezing and other "axial" symptoms, usually do not respond to dopaminergic therapy and may be mediated by nondopaminergic systems (Bonnet 2000; Kompoliti et al 2000). It is very likely that with better understanding of the mechanisms of neurodegeneration, novel and more effective therapeutic strategies will be available in the near future.

\section{Adjunctive therapy}

While neuroprotective strategies slow or halt the progression of the disease, these strategies must be implemented early (Schapira 2004). Clinically relevant effects of putative neuroprotective agents are difficult to measure and so more and more studies utilize not only clinical ratings, but also ancillary techniques, such as 18F-L-DOPA PET and 123I $\beta$-CIT SPECT, to longitudinally measure the progression of nigrostriatal degeneration.

The finding that deprenyl (selegiline) prevents MPTPinduced Parkinsonism has stimulated interest in antioxidative therapy as a means of retarding progression of $\mathrm{PD}$ and other neurodegenerative diseases. In the largest clinical trial designed to address the potential protective effects of selegiline, "Deprenyl and Tocopherol Antioxidative Therapy of Parkinsonism" (DATATOP), the outcomes of treatments with deprenyl, alpha-tocopherol (vitamin E) and a combination of these putative antioxidants in comparison to a placebo were compared. The results showed that deprenyl-treated patients reached the end-point 9 months after the group treated with placebo or tocopherol. The waning of the effects of selegiline on delaying end-point after the first year, coupled with slight but significant improvement in motor performance after initiation of selegiline and slight (nonsignificant) worsening after 1-month washout, has been used as an argument in favor of predominantly symptomatic rather than protective effect. In a follow up study, levodopa treated PD patients who have been taking selegiline for 7 years, compared to those who were changed to placebo after 5 years, showed significantly slower decline, less wearing off, on-off motor fluctuations, and less freezing, but more dyskinesias (Shoulson et al 2002). This is consistent with another study of the same patient population, which showed that patients randomized to selegiline had a lower risk of freezing than those assigned to placebo (Giladi et al 2001).

In clinical studies, rasagiline, a selective, irreversible MAO B inhibitor, provides a modest benefit as an adjunctive therapy in PD patients experiencing levodopa related motor fluctuations. A double-blind, placebo-controlled trial showed that after a 10-week treatment with rasagiline, 12 of $43(28 \%)$ of patients had an improvement in total UPDRS score of $30 \%$ or greater, compared with none in the placebo group ( $p<0.05$ ) (Stern et al 2004). In an 18-week, doubleblind trial of 687 patients randomized to receive once-daily rasagiline, entacapone (with each dose of levodopa), or placebo (the LARGO trial), both rasagiline and entacapone reduced "off" time by 1.2 hours as compared with placebo ( 0.4 hour reduction, $p \leq 0.0001)$. The mean daily dose of levodopa was reduced on rasagiline and on entacapone, and was increased on placebo (Rascol et al 2005). Other variables showed that rasagiline was superior to placebo and to entacapone in reducing UPDRS motor score, and at least as effective as entacapone in reducing "off” time compared to baseline (Parkinson Study Group 2005).

In one study of 80 patients with early PD, Shults and colleagues (2002) found that in comparison to placebo, $1200 \mathrm{mg}$ of CoQ10 was associated with a slower decline in UPDRS and a positive trend in decline UPDRS decline favoring CoQ10. In this study, patients never previously treated with L-DOPA were randomized to receive placebo or one of three doses of CoQ10: 300, 600, or $1200 \mathrm{mg} /$ day. In addition, they were also receiving $300 \mathrm{IU}$ vitamin $\mathrm{E}$, which was thought to act as a carrier of CoQ10 across the bloodbrain barrier. The patients were followed for 16 months or until they required L-DOPA. The drug was found to be well tolerated, and there was no difference in adverse effects between CoQ10 and placebo. When compared to baseline, 


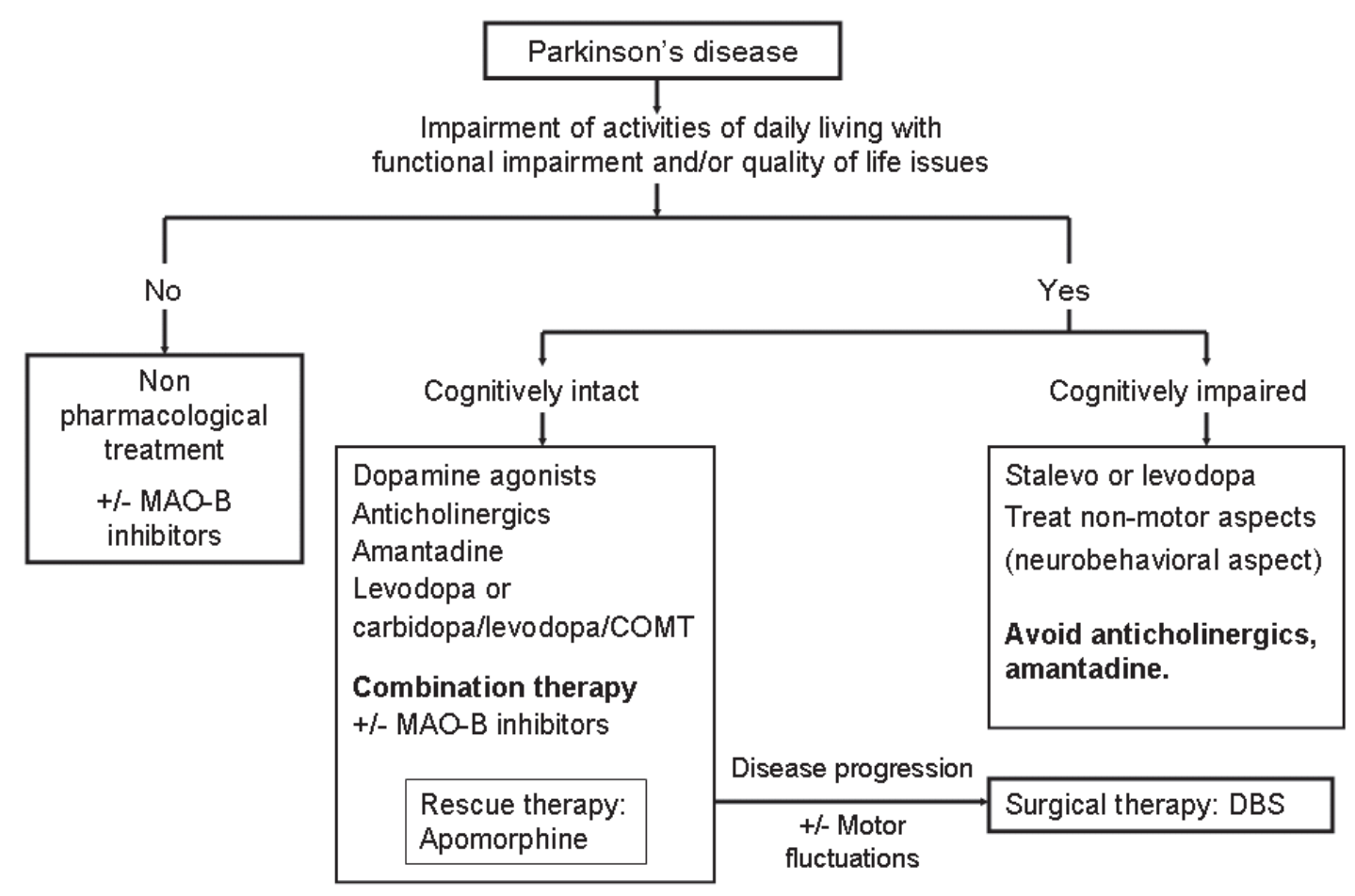

Figure 2 Treatment guidelines for the progressive stages of Parkinson's disease.

Abbreviations: COMT, catechol-o-methyl-transferase; DBS, deep brain stimulation; MAO, monoamine oxidase.

the group receiving placebo deteriorated by 12 points in the UPDRS, whereas patients receiving $1200 \mathrm{mg}$ deteriorated by only 6.7 points. Furthermore, patients receiving CoQ10 had on the average $44 \%$ less decline in mental function, movement and ability to perform daily living tasks than the placebo group. This difference was statistically significant only for the $1200 \mathrm{mg} /$ day group, but there was no difference between placebo and the lower dose groups. Treatment did not delay the disability severe enough to require L-DOPA. The study was highly suggestive, yet was not definitive. There is no evidence that vitamin supplements, including vitamin $\mathrm{C}$ and $\mathrm{E}$, or carotenoids reduce the risk of $\mathrm{PD}$ (Zhang et al 2002). Further studies are needed to determine whether CoQ10 and other quinines, such as idebenone, may serve as either substitutive electron carriers or antioxidant compounds in disorders with known or suspected mitochondrial dysfunction.

\section{Antiglutamatergic drugs}

Interactions between dopamine and glutamate in striatal medium spiny neurons have been found to play an important role in PD, and there is considerable theoretical and experimental support for the use of glutamate antagonists as potential neuroprotective drugs (Chase and Oh 2000). Several studies have demonstrated that the neuronal activity is increased in the subthalamic nucleus (STN) and in the internal segment of globus pallidum (GPi) of parkinsonian animals and humans (Obeso et al 2000a). Since STN provides excitatory, glutamatergic input to $\mathrm{GPi}$, glutamate inhibition would be expected to improve Parkinsonism. Some studies indeed have shown that N-methyl-D-aspartate (NMDA) antagonists prevent the selective toxicity of MPP+ and that an ablation of STN attenuates the loss of DA neurons in rats exposed to the mitochondrial toxin 3-nitroproprionic acid (3-NP) or the catecholamine toxin (6-OHDA) (Nakao et al 1999). Certain anticholinergic drugs and amantadine posses NMDA-blocking properties and amantadine have been shown to not only ameliorate parkinsonian symptoms, but also to improve motor fluctuations and levodopa induced dyskinesias (Verhagen Metman et al 1999; Luginger et al 2000).

\section{Future therapies}

One particularly promising therapeutic and potentially neuroprotective approach involves the use of neurotrophic factors, such as neurturin (NTN) (Kordower et al 2006) and the glial cell-line-derived neurotrophic factor (GDNF) (Gash et al 1998). These trophic factors have been reported to enhance the survival of midbrain dopaminergic neurons in vitro and to rescue degenerating neurons in vivo. These encouraging observations have led to a pilot human trial of GDNF administered by an implanted intracerebroventricular 
catheter in patients with moderately advanced PD conducted in several centers in North America. However, because of lack of observed efficacy and frequent occurrence of nausea, anorexia, tingling (L'hermitte's sign), hallucinations, and depression, these trials were suspended (Nutt et al 2003). In a one-year follow-up of five patients with PD in whom GDNF was continuously infused directly into the putamen, there were no serious clinical side effects, a 39\% improvement in the off-medication motor sub-score of the UPDRS and a $61 \%$ improvement in the activities of daily living sub-score. Furthermore, levodopa-induced dyskinesias were reduced by $64 \%$ and, in contrast to fetal implants (see below) there were no off dyskinesia. This clinical improvement was accompanied by a $28 \%$ increase in putamen PET F-DOPA uptake (Gill et al 2003). Results from a recently completed multicenter trial, however, show no benefit from GDNF (Lang et al 2006) and further studies have been suspended because of evidence of cerebellar toxicity in experimental primates.

CERE-120 is an adeno-associated virus type 2 (AAV2) vector encoding human NTN (AAV2-NTN). In a recent open label trial, 12 patients with advanced $P D$ were stereotactically administered bilateral intraputaminal CERE-120 (Marks et al 2006). Two doses were evaluated, with six patients in each cohort. UPDRS and off-medication motor scores improvement of $20 \%$ and $25 \%$, respectively, were observed at both three and six months in the low dose cohort. Improvement in the total off-medication motor scores was approximately $26 \%$ and $22 \%$, respectively, at three months in the high dose cohort. Rigidity and bradykinesia measurements showed the greatest improvement, off-time was reduced by $27 \%$ and "on"-time was doubled without dyskinesias through six months in the low dose cohort, with similar trends in the high dose cohort. The intraputaminal administration of CERE-120 was well tolerated. Ongoing double-blind clinical trials are under way to determine the efficacy and safety of CERE-120 in patients with PD.

In addition to neurotrophic factors, other therapeutic possibilities currently being investigated include retinal pigment epithelial cells (hRPE). These cells, located in the inner layer of neural retina, produce levodopa. When attached to cross linked gelatin microcarriers (Spheramine ${ }^{\circledR}$ ) and implanted stereotactically into the striatum, the cells have improved parkinsonian symptoms in rodents, nonhuman primates and parkinsonian patients. A pilot, open label study of 6 patients showed $48 \%$ improvement in the UPDRS motor score after implantation in the most affected postcommissural putamen. All patients tolerated the implantation of Spheramine well and demonstrated improvement. At 6, 9, and 12 months postoperatively, the mean UPDRS-Motor score “off”, the primary outcome measure, improved 33\%, $(n=6), 42 \%(n=6)$, and $48 \%(n=3)$, respectively. No "off-state" dyskinesias were observed (Watts et al 2003). The 48\% improvement was maintained at 24 months (Stover et al 2005a).

\section{Treatment of neurobehavioral features}

Treatment of cognitive deficits associated with PD is as challenging as the treatment of Alzheimer's disease and other dementias. While the general assumption has been that cognitive deficits are a feature of late-stage PD, clinically inapparent cognitive changes on neuropsychiatric testing may be found (Williams-Gray et al 2006). With the introduction of cholinesterase inhibitors such as donepezil (Aricept ${ }^{\circledR}$ ), rivastigmine $\left(\right.$ Exelon $\left.^{\circledR}\right)$, and galantamine (Reminyl ${ }^{\circledR}$,) and the NDMA antagonist memantine (Namenda ${ }^{\circledR}$ ) (Reisberg et al 2003), it is possible that cognition, orientation and language function will improve, and that such improvement will lead to a meaningful improvement in function. Both donepezil and rivastigmine improve cognition to the same effect, but donepezil is better tolerated (Wilkinson et al 2002). The largest and bestdesigned study of rivastigmine in dementia associated with PD involved 541 patients enrolled in a 24-week randomized, multicenter, double-blind clinical trial (Emre et al 2004). The patients had a relatively mild dementia (MMSE 10-24), with onset of dementia about 2 years after onset of PD symptoms. The mean ADAS-cog score, the primary efficacy variable, improved by 2.1 points in the rivastigmine group, compared to 0.7 in the placebo group ( $p<0.001$ ), and the MMSE improved by 0.8 in the rivastigmine group and worsened by 0.2 in the placebo group $(p=0.03)$. At the end of the study, $55.5 \%$ were receiving 9 to $12 \mathrm{mg}$. The adverse effects that were significantly more frequent in the rivastigmine group were nausea, vomiting, dizziness, and tremor.

Rivastigmine should be started at $1.5 \mathrm{mg}$ BID and increased at 4-week intervals to $3 \mathrm{mg}$ BID and eventually to $6 \mathrm{mg}$ BID. This slow titration is designed to prevent potential side effects such as nausea, vomiting, agitation and weight loss. In a recent database study conducted by the VA, over 4.5 million subjects were reviewed, with analysis restricted to those patients over 65 years who did not have a prior diagnosis of Alzheimer's or Parkinson's disease. The use of simvastatin was associated with a reduction in incident dementia; and after adjusting for cardiovascular disease, hypertension, diabetes and the use of neuroleptics, simvastatin was also observed to be associated with a reduced incidence of PD (Wolozin et al 2007).

In addition to motor side effects related to levodopa therapy, many PD patients experience a variety of psychiatric 
reactions, particularly psychosis with agitation, delusions, paranoid beliefs and hallucinations (Fénelon et al 2000). In PD patients with new symptoms of confusion or psychosis, factors unrelated to PD and PD-related treatment must be identified prior to modifying therapies or adding antipsychotics. Psychotic symptoms can be controlled by reducing the dosage of dopaminergic drugs (levodopa, dopamine agonists) and eliminating all other drugs that are not absolutely essential. Borek and colleagues (2007) suggested eliminating anticholinergics first, followed by amantadine, monoamine oxidase inhibitors, dopamine agonists, COMT inhibitors, then reducing the amount of levodopa. Atypical antipsychotics offer the best strategy for controlling drug-induced psychosis without the need to adjust the dosage of dopaminergic drugs (Friedman and Factor 2000). While quetiapine has been used successfully based on open label findings, two double-blind studies did not find significant differences in the management of psychosis in patients with $\mathrm{PD}$ when compared with placebo (Ondo et al 2005a; Rabey et al 2007). Other atypical antipsychotics such as risperidone, olanzapine, ziprasidone and aripiprazole have been found to worsen motor performance without demonstrating statistically significant improvement of dopamine-induced psychosis (Rich et al 1995; Breier et al 2002; Ondo et al 2002; Friedman et al 2006). This is in contrast with studies where quetiapine (Mancini et al 2004; Merims et al 2006) and ziprasidone (Gomez-Esteban et al 2005) improved the psychotic symptoms without causing variation in their motor performance. Treatment with atypical neuroleptics, such as clozapine, has been associated with improved prognosis (Factor et al 2003). The use of clozapine has been limited due to the potential to cause agranulocytosis, which is an idiosyncratic reaction, and not dose-related (Fernandez et al 2003). Cholinesterase inhibitors such as donepezil (Fabbrini et al 2002) and rivastigmine (Reading et al 2001) have been found to be beneficial, without worsening of the UPDRS, in small, open label studies.

Depression has an estimated prevalence of $40 \%-50 \%$, and is one of the most common behavioral disturbances in PD (Tandberg et al 1996; Zesiewicz et al 1999). It may present at any stage of the disease, and may precede the appearance of motor symptoms (Cummings 1992). Risk factors for PD-related depression include female sex, a history of depression, early-onset PD (ie, before the age of 55 years) and "atypical" Parkinsonism (eg, prominent akinesia/rigidity or extensive vascular disease) (Weintraub et al 2007). The subthalamic nucleus has been implicated in mood disorders in PD patients, as deep brain stimulation (DBS) has been found to have antidepressant, depressive and mania-inducing effects (Takeshita et al 2005). Because depressive symptoms, such as flat affect, anxiety, cognitive impairment, fatigue, weight loss, and sleep disturbances often overlap with those of PD, diagnosis is often under-recognized. In a cohort of over 400 newly diagnosed patients with PD, followed for an average of 14.6 months, $27.6 \%$ (114) screened positive for depression. Of these, $40 \%$ were neither treated nor referred for psychiatric evaluation (Ravina et al 2007). The same study found depression to be a significant predictor of more impairment in activities of daily living and increased need for symptomatic therapy of PD. Given the effects of depression on motor function and quality of life, prompt recognition and early treatment are integral aspects in the management of PD. Tricyclic antidepressants, while not necessarily the drug of first choice (due to their side effect panel), may be considered in the treatment of depression in PD (Miyasaki et al 2006). The anticholinergic properties of the TCAs may be helpful in PD patients with drooling, overactive bladder and insomnia. Selective serotonin reuptake inhibitors (SSRIs) have been recommended as first-choice antidepressants in PD considering their tolerability, and acceptable side effect profile and drug-drug interactions (Borek et al 2007). There are some conflicting data whether the selective serotonin receptor inhibitors (SSRIs) exacerbate Parkinsonism, but a study of 30 PD patients, (Ceravolo et al 2000) found paroxetine, one of the typical SSRIs, at doses of $20 \mathrm{mg} / \mathrm{day}$, to be safe and effective in the treatment of depression associated with PD. Caution must be exercised when using selegiline in combination with SSRIs and TCAs, as there is a small but increased risk of developing a serotonin syndrome. Antiparkinsonian medications, such as selegiline (Allain et al 1991; Baronti et al 1992), bromocriptine (Jouvent 1983), pergolide (Rektorova et al 2003) and pramipexole (Barone et al 2003) have been reported to have antidepressant effects.

Like depression, anxiety has been reported in up to $40 \%$ of PD patients (Stein et al 1990; Vasquez et al 1993); similarly, anxiety may precede the appearance of motor symptoms by many years, and usually before onset of depression (Shiba et al 2000). The most common anxiety disorders in PD are panic disorder, generalized anxiety disorder and social phobia (Vasquez et al 1993; Richard 2005). Anxiety has been reported to occur in patients experiencing "on-off” states, particularly the "off” period (Stein et al 1990; Vasquez et al 1993). In these instances, adjustment of antiparkinsonian medications may be effective in managing anxiety. SSRIs, with their favorable side effect profile, are used as first-line treatment; onset of anxiolytic effects usually occurs between 2 and 4 weeks, with dose adjustment after 1 month (Borek et al 2007). 
Apathy is characterized by loss of motivation, and diminished goal-directed behavior. It affects over $10 \%$ of PD patients, and is believed to be due to prefrontal lobe dysfunction (Starkstein et al 1992; Luck et al 2002). Apathy is independent of depression and anxiety, being mainly determined by cognitive impairment (Dujardin et al 2007). With no known treatment, antidepressants are given in the hope that the apathy is a component of a depressive syndrome (Borek et al 2007).

Impulse control disorders (ICDs) have been described in PD patients treated with dopamine agonists (Voon 2004), and consist of punding, compulsive gambling, compulsive shopping, compulsive eating, and hypersexuality. The first impulsive behavior described in patients with PD was punding and was initially attributed to treatment with levodopa (Friedman 1994). Punding behavior, an intense fascination with repetitive, aimless behavior, as first described in amphetamine and cocaine abuse, is presumed to be secondary to dopaminergic excess. It has since been reported to occur in PD patients treated with dopamine agonists (Kurlan 2004). The incidence of punding varies from $1.4 \%$ to $14 \%$ (Evans et al 2004; Miyasaki et al 2007). Evans and colleagues (2004) noted that punding in patients with PD occurred rather frequently and was associated with the use of either or both L-DOPA and dopamine agonists. They also suggested that requirements for large doses of dopaminergic therapy, frequent rescue doses and the use of rescue medications overnight should raise suspicion and prompt queries into patients' pastimes. Patients complaining of sleep disturbance should also be asked specifically how they cope with periods of sleep deprivation. Punding may also be suspected if the addition of further dopaminergic therapy at night exacerbates rather than benefits patient's insomnia. In the study by Evan and colleagues (2004), patients with L-DOPA equivalent units (LEU) greater than or equal to 800 were recruited. Of these, punders were more likely to use apomorphine and cabergoline, and less likely to use entacapone. Increasing clinical severity of the punding behavior significantly correlated with higher total daily LEU dose, younger age, reduced sleep time overnight, and average number of daily rescue doses suggesting patients with punding may have dopa dysregulation.

Pathological gambling has been attributed by some to the use of dopamine agonists, but this putative association has not been confirmed (Driver-Dunckley et al 2003; Dodd et al 2005). Younger age at PD onset, higher novelty seeking traits, and a personal or family history of alcohol use disorders have been found to be associated with a greater risk for pathological gambling with dopamine agonists (Voon et al 2007). Contrary to typical obsessive-compulsive disorders, punding and other ICDs respond poorly to SSRIs, clomipramine and antipsychotics (Evans et al 2004; Kurlan 2004). Treatment options such as decreasing the dose of DA, or switching to a different DA, produce the best results (Borek et al 2007; Miyasaki et al 2007).

Excessive daytime sleepiness (EDS), sleep fragmentation, altered dreaming and RBD affect over three-quarters of PD patients (Friedman and Chou 2004). The existence of other causes of EDS, such as obstructive sleep apnea, use of sedative medication and the presence of concurrent medical illnesses must be established and treated. Both pramipexole and ropinirole (and possibly other DA agonists) have been associated with irresistible sleep attacks leading to motor vehicle mishaps (Frucht et al 1999; Hauser et al 2000; Brodsky et al 2003). Sleepiness correlated significantly with a longer duration of PD, more advanced PD, male gender, and the use of any DA (Ondo et al 2001). The soporific effects of the three most common DA (pramipexole, ropinirole, and pergolide) and even levodopa were similar (Ondo et al 2001; Brodsky et al 2003). The risk of accidents can be prevented by discussing this potential side effect with the patient and their family, by warning them not to drive if they feel drowsy, and by encouraging them to take short naps on the side of the road as needed (Reyner and Horne 1998). Modafinil (Provigil ${ }^{\circledR}$ ) at 100 to $200 \mathrm{mg}$ twice a day is effective in reversing the excessive daytime drowsiness and the sedative effects of anti-PD medications (Hauser et al 2000; Ondo et al 2001), although a recent double-blind, placebo-controlled study failed to significantly improve EDS in PD patients when compared to placebo (Ondo et al 2005b). Vivid and often violent dreams, with prominent motor activity and loss of normal atonia during REM sleep characterize RBD. TCAs, SSRIs and MAO inhibitors can induce or aggravate RBD. Clonazepam is considered the treatment of choice with effectiveness in about $90 \%$ of patients (Gagnon et al 2006).

The nonmotor side effects of levodopa, such as hallucinations and orthostatic hypotension, are dose-related and these adverse effects could offset the potential benefits of prolonged motor response. In addition to adjusting levodopa dosing, reductions of anticholinergic drugs may also ameliorate dyskinesias. Dystonia often improves with the administration of baclofen, anticholinergic drugs, DA agonists, lithium, and local injections of botulinum toxin.

\section{Neurosurgical treatments of Parkinson's disease}

It is beyond the scope of this manuscript to comprehensively review neurosurgical treatment of PD. Only a brief review 
will be provided here and the reader is referred to other published literature on for additional information about this important therapeutic strategy. The renewed interest in surgical treatment of movement disorders has been stimulated in part by improved understanding of the functional anatomy underlying motor control, as well as refinement of methods and techniques in neurosurgery, neurophysiology, and neuroimaging (Jankovic 2001; Krauss et al 2001).

Besides thalamotomy and pallidotomy, another promising surgical approach for the treatment of tremors and other movement disorders is high-frequency DBS via electrodes implanted in the VIM nucleus of the thalamus, GPi, STN or other subcortical nuclei. The mechanism of electrical stimulation is not known, but the following explanations have been offered: 1) disruption of the network ("jamming" of feedback loop from the periphery), 2) depolarization block, 3 ) preferential activation of inhibitory neurons, and 4) a functional ablation by desynchronizing a tremorogenic pacemaker.

Thalamic stimulation appears to be particularly effective in the treatment of parkinsonian tremor and ET. Our experience at Baylor is similar to that reported in other centers. In a blinded and open label trial of unilateral thalamic DBS in 33 patients (14 ET and $19 \mathrm{PD}$ ) with severe tremor refractory to conventional therapy, both groups of patients demonstrated a statistically significant decrease $(p<0.0001)$ in observed contralateral arm tremor, respectively (Ondo et al 1998). All measures of tremor, including writing samples, pouring tests, subjective functional surveys, and disability scores significantly improved. To compare thalamic DBS with thalamotomy, Schuurman and colleagues (2000) conducted a prospective, randomized study of 68 patients with $\mathrm{PD}, 13$ with ET, and 10 with multiple sclerosis. They found that the functional status improved more in the DBS group as compared to the thalamotomy group and tremor was suppressed completely or almost completely in both the DBS group and in the thalamotomy group. Although one patient in the DBS group died after an intracerebral hemorrhage, DBS was associated with significantly fewer complications than thalamotomy. In addition to improving distal tremor associated with PD and ET, VIM DBS can effectively control ET head tremor, which usually does not respond to conventional therapy.

Since bilateral thalamotomy can cause hypophonia, dysarthria, and dysphagia, DBS is now considered the best alternative, particularly in those patients who require bilateral procedures. Thalamotomy has the advantage over DBS in that there is no need for hardware, and for patients with disabling bilateral tremor, unilateral thalamotomy in combination with contralateral DBS may offer the optimal tremor control with the fewest adverse side effects. Chronic stimulation of the thalamus appears to be well tolerated and the risk of local gliosis is minimal (Haberler et al 2000), although more extensive damage has been rarely reported (Henderson et al 2002). Because of the ability to customize the stimulation parameters and the relatively low risk of complications, DBS is now considered the preferred surgical treatment for disabling PD-related tremor or ET.

Several studies have demonstrated that DBS of the GPi and STN improves parkinsonian symptoms and prolongs the "on" time (Linizasaro 2003), as well as other aspects of quality of life (Diamond and Jankovic 2005). The relative safety and efficacy of STN vs GPi DBS, however, has been compared formerly in only small studies (Burchiel et al 1999). Although no difference between the two targets was found by Burchiel, their study had insufficient power to detect a difference between the two groups. The "off" UPDRS motor score has been reported to improve by $34 \%$ to $60 \%$ and the UPDRS ADL score by $30 \%-50 \%$ in patients undergoing STN or GPi DBS. Furthermore, dyskinesia has been reported to markedly improve, largely as a result of about $50 \%$ reduction in daily levodopa dosage.

Both STN and GPi DBS improve the off medication UPDRS motor score (Anderson et al 2005), worsen the "on" motor states of the motor UPDRS, activities of daily living and gait, and improve the "off" medication UPDRS respect to the baseline (Rodriguez-Oroz et al 2005). Neither the STN nor the GPi DBS improves the "on" medication function. In a five year follow up after bilateral STN DBS on the first 49 consecutive patients, Krack and colleagues (2003) found marked improvement in motor function while off medications and in dyskinesia while on medications. At five years, the LEU dose and the duration and severity of levodopa-induced dyskinesia were reduced compared to baseline. In a study of 30 patients with PD Hoehn and Yahr stages 3-4 while off medication randomized to either STN or GPi DBS, 89\% improvement of dyskinesias in the GPi DBS group was observed, while in the STN DBS group, dyskinesias improved by 62\% (Anderson et al 2003). Bradykinesia improved more in the STN group when compared to GPi stimulation (Anderson et al 2003), and STN DBS was associated to a greater decrease in levodopa dosage (Rodriguez-Oroz et al 2005), but more severe speech impairment, postural instability, and cognitive decline (Anderson et al 2003; Rodriguez-Oroz et al 2005). Since improvements in dyskinesia usually require a reduction in levodopa dosage, unilateral STN or GPi DBS is impractical because the side of the body contralateral to the unstimulated 
Table 4 Experimental therapeutics of Parkinson's disease

MAOI: Safinamide
DA: Sumanirole
DA reuptake blockers: NS 2330
Antidyskinesia drugs: Sarizotan, istradefylline (KW-6002), fipamazole
(JP-1730), levetiracetam
Trophic drugs: GPI I485, CERE- I20, GDNF
Neuroprotective drugs: CoQ I0,TCH 346, CEP-1347, minocycline,
creatine
Surgery: fetal grafts, Spheramine ${ }^{\circledR}$

Abbreviations: DA, dopamine agonists; MAO, monoamine oxidases.

side would clearly worsen. Bilateral STN DBS appears to be more effective than unilateral STN DBS in improving Parkinsonism, but unilateral STN DBS may be appropriate for patients with asymmetric parkinsonian symptoms including a high amplitude tremor (Kumar et al 1999; Stover et al 2005b; Diamond et al 2007). In addition to improving limb signs and the cardinal signs of PD, bilateral STN DBS has been found to also improve axial parkinsonian symptoms, particularly arising from chair and gait, but speech, neck rigidity, abnormal posture, and postural instability also improved (Bejjani et al 2000).

Except for mild deficit in lexical fluency, STN or GPi DBS does not appear to adversely affect cognitive performance (Pillon et al 2000), but some older patients have been found to have an impairment in frontal executive function (SaintCyr et al 2000). Although bilateral STN is clearly effective in improving the cardinal as well as other parkinsonian symptoms, the procedure does not necessarily improve all the symptoms and, as a result of progression of cognitive, speech, and other deficits frequently associated with PD, the quality of life may not substantially improve in patients who exhibit these additional features (Hariz et al 2000).

\section{Other therapeutic approaches}

Besides conventional pharmacologic and surgical treatments, there are many other strategies currently being explored in the treatment of some PD symptoms (Jankovic 1999; Jankovic 2001) (Table 4). Speech therapy designed to stimulate increased vocal fold adduction with instructions to "increase loudness", the so called Lee Silverman Voice Treatment (LSVT), using various verbal cues to regulate speech volume, and percutaneous collagen augmentation of the vocal folds (Hill et al 2003) have been used successfully to treat the hypophonic, hypokinetic dysarthria associated with PD.

Although this review has attempted to highlight the most recent advances in the treatment of PD, it is important to note that new treatments are not necessarily better than the established conventional therapy and that the treatment options must be individualized and tailored to the needs of each individual patient (Jankovic 2000, 2002b).

\section{Disclosure}

The authors report no conflicts of interest.

\section{References}

Allain H, Cougnard J, Neukirch HC, et al. 1991. Selegilene in de novo parkinsonian patients: the French selegiline multicenter trial. Acta Neurol Scand, 136:73-8.

Anderson VC, Burchiel KJ, Hogarth P, et al. 2005. Pallidal vs subthalamic nucleus deep brain stimulation in Parkinson disease. Arch Neurol, 62:554-60.

Assal F, Spahr L, Hadengue A, et al. 1998. Tolcapone and fulminant hepatitis. Lancet, 19:958.

Barone I, Rektor I, Bares M, et al. 2003. Pramipexole and pergolide in the treatment of depression in Parkinson's disease: a national multicentre prospective randomized study. Eur J Neurol, 10:399-406.

Baronti F, Davis TL, Boldry RC, et al. 1992. Deprenyl effects on levodopa pharmacodynamics, mood and free radical scavenging. Neurology, 42:541-4

Bejjani BP, Gervais D, Arnulf I, et al. 2000. Axial parkinsonian symptoms can be improved: the role of levodopa and bilateral subthalamic stimulation. J Neurol Neurosurg Psychiatry, 68:595-600.

Bhatia KP, Münchau A, Brown P. 1999. Botulinum toxin is a useful treatment in excessive drooling of saliva. J Neurol Neurosurg Psychiatry, 67:697.

Blindauer K, and the Parkinson Study Group. 2003. Delayed response to levodopa and response failures account for a large percentage of daily off time in advanced Parkinson's disease patients with motor fluctuations. Neurology, 60:81-2.

Bonnet AM. 2000. Involvement of non-dopaminergic pathways in Parkinson's disease. Pathophysiology and therapeutic implications. CNS Drugs, 13:351-64.

Borek LL, Chou KL, Friedman JH. 2007. Management of the behavioral aspects of Parkinson's disease. Expert Rev Neurother, 7:711-25.

Breier A, Sutton VK, Feldman PD, et al. 2002. Olanzapine in the treatment of dopamimetic-induced psychosis in patients with Parkinson's disease. Biol Psychiatry, 52:438-45.

Brodsky MA, Godbold J, Roth T, Olanow CW. 2003. Sleepiness in Parkinson's disease: A controlled study. Mov Disord, 18:668-72.

Brooks DJ. 2000. Dopamine agonists: their role in the treatment of Parkinson's disease. J Neurol Neurosurg Psychiatry, 68:685-90.

Burchiel KJ, Anderson VC, Favre J, et al. 1999. Comparison of pallidal and subthalamic nucleus deep brain stimulation for advances Parkinson's disease: results of a randomized, blinded pilot study. Neurosurgery, 45:1375-84.

Ceravolo R, Nuti A, Piccini A, et al. 2000. Paroxetine in Parkinson's disease: Effects on motor and depressive symptoms. Neurology, 55:1216-8.

Chase TN, Oh JD. 2000. Striatal dopamine- and glutamate-mediated dysregulation in experimental parkinsonism. TINS, 23:86-91.

Cristina S, Zangaglia R, Mancini F, et al. 2003. High-dose ropinirole in advanced Parkinson's disease with severe dyskinesias. Clin Neuropharmacol, 26:146-50.

Cummings JL. 1992. Depression and Parkinson's disease: a review. Am J Psychiatry, 149:443-54.

Diamond A, Jankovic J. 2005. The effect of deep brain stimulation on quality of life in movement disorders. J Neurol Neurosurg Psychiatry, 76:1188-93.

Diamond A, Shahed J, Jankovic J. 2007. The effects of subthalamic nucleus deep brain stimulation on parkinsonian tremor. J Neurol Sci, 260:199-203. 
Dodd ML, Klos KJ, Bower JH, et al. 2005. Pathological gambling caused by drugs used to treat Parkinson disease. Arch Neurol, 62:1377-81.

Driver-Dunckley E, Samanta J, Stacy M. 2003. Pathological gambling associated with dopamine agonist therapy in Parkinson's disease. Neurology, 61:422-3.

Dujardin K, Sockeel P, Devos D, et al. 2007. Characteristics of apathy in Parkinson's disease. Mov Disord, 22:778-84.

Ellison RH. 1998. Dear health professional letter regarding appropriate use of Tasmar. Nutley, NJ: Roche Laboratories Inc.

Emre M, Aarsland D, Albanese A, et al. 2004. Rivastigmine for dementia associated with Parkinson's disease. N Engl J Med, 351:2509-18.

Etminan M, Gill S, Samii A. 2003. Comparison of the risk of adverse events with pramipexole and ropinirole in patients with Parkinson's disease: a meta-analysis. Drug Saf, 26:439-44.

Evans AH, Katzenschlager R, Paviour DC, et al. 2004. Punding in Parkinson's disease: its relation to the dopamine dysregulation syndrome. Mov Disord, 19:397-405.

Fabbrini F, Barbanti P, Aurilia C, et al. 2002. Donepezil in the treatment of hallucinations and delusions in Parkinson's disease. Neurol Sci, 23:41-3.

Factor SA, Feustel PJ, Friedman JH, et al. 2003. Longitudinal outcome of Parkinson's disease patients with psychosis. Neurology, 60:1756-61.

Fahn S. 2000. The spectrum of levodopa-induced dyskinesias. Ann Neurol, 47:2-11.

Fénelon G, Mahieux F, Huon R, Ziégler M. 2000. Hallucinations in Parkinson's disease. Prevalence, phenomenology and risk factors. Brain, 123:733-45.

Fernandez HH, Trieschmann ME, Friedman JH. 2003. Treatment of psychosis in Parkinson's disease; safety considerations. Drug Saf, 26:643-59.

Food and Drug Administration. 1998. New Warnings for Parkinson's Drug Tasmar. Rockville, MD. November 16, T98-81.

Friedman JH, Berman RM, Goetz CG, et al. 2006. Open-label flexibledose pilot study to evaluate the safety and tolerability of aripiprazole in patients with psychosis associated with Parkinson's disease. Mov Disord, 21:2078-81.

Friedman JH, Chou KL. 2004. Sleep and fatigue in Parkinson's disease. Parkinsonism Relat Disord, 10:27-35.

Friedman JH, Factor SA. 2000. Atypical antipsychotics in the treatment of drug-induced psychosis in Parkinson's disease. Mov Disord 15:201-11.

Friedman JH. 1994. Punding on levodopa. Biol Psychiatry, 36:350-1.

Frucht S, Rogers JD, Greene PD, et al. 1999. Falling asleep at the wheel: Motor vehicle mishaps in persons taking pramipexole and ropinirole. Neurology, 52:1908-10.

Gagnon JF, Postuma RB, Montplaisir J. 2006. Update on pharmacology of REM sleep behavior disorder. Neurology, 67:742-7.

Gash DM, Zhang Z, Gerhardt G. 1998. Neuroprotective and neurorestorative properties of GDNF. Ann Neurol, 44:121-5.

Giladi N, McDermott MP, Fahn S, et al; and the Parkinson Study Group. 2001. Freezing of gait in PD. Prospective assessment of the DATATOP cohort. Neurology, 56:1712-21.

Gill SS, Patel NK, Hotton GR, et al. 2003. Direct brain infusion of glial cell line-derived neurotrophic factor in Parkinson disease. Nat Med, 9:589-95.

Gomez-Esteban JC, Zarranz JJ, Velasco F, et al. 2005. Use of ziprasidone in patients with psychosis. Clin Neuropharmacol, 28:111-4.

Grandas F, Hernandez B; PRACTICOMT Study Group. 2007. Long-term effectiveness and quality of life improvement in entacapone-treated Parkinson's disease patients: the effects of an early therapeutic intervention. Eur J Neurol, 14:282-9.

Grünblatt E, Mandel S, Berkuzki T, et al. 1999. Apomorphine protects against MPTP-induced neurotoxicity in mice. Mov Disord, 14:612-8.

Haberler C, Alesch F, Mazal PR, et al. 2000. No tissue damage by chronic deep brain stimulation in Parkinson's disease. Ann Neurol, 48:372-6.
Hariz MI, Johansson F, Shamsgovara P, et al. 2000. Bilateral subthalamic nucleus stimulation in a parkinsonian patient with preoperative deficits in speech and cognition: Persistent improvement in mobility but increased dependency: A case study. Mov Disord, 15:136-9.

Hauser RA, Wahba MN, Anderson WM. 2000. Modafinil treatment of pramipexole-associated somnolence. Mov Disord, 15:1269-71.

Hauser RA. 2004. Levodopa/carbidopa/entacapone (Stalevo). Neurology, 62:64-71.

Heikkinen H, Varhe A, Lyly V, et al. 2003. New levodopa, carbidopa and entacapone combination tablets. European J Neurology, 10:164.

Henderson JM, Pell M, O'Sullivan DJ, et al. 2002. Postmortem analysis of bilateral subthalamic electrode implants in Parkinson's disease. Mov Disord, 17:133-7.

Hill MP, Bezard E, Brotchie JM, et al. 2003. The antiepileptic, levetiracetam (Keppra), modulates the process of priming for L-dopa-induced dyskinesia in MPTP-lesioned marmosets. European J Neurology, 10:164.

Jankovic J, Watts RL, Martin W, et al. 2007. Transdermal rotigotine: double-blind, placebo-controlled trial in Parkinson disease. Arch Neurol, 64:676-82.

Jankovic J. 1999. New and emerging therapies for Parkinson's disease. Arch Neurol, 56:785-90.

Jankovic J. 2000. Parkinson's disease therapy: Tailoring choices for early and late disease, young and old patients. Clin Neuropharmacol, 23:252-61.

Jankovic J. 2001. Surgery for Parkinson's disease and other movement disorders: Benefits and limitations of ablation, stimulation, restoration, and radiation. Arch Neurol, 58:1970-2.

Jankovic J. 2002. Levodopa strengths and weaknesses. Neurology, 58: $19-32 \mathrm{a}$.

Jankovic J. 2002. Therapeutic strategies in Parkinson's disease. In: Jankovic J, Tolosa E, (eds.) Parkinson's Disease and Movement Disorders, 4th edition, Philadelphia, PA: Lippincott Williams and Wilkins. p116-151b.

Jankovic J. 2005. Motor fluctuations and dyskinesias in Parkinson's disease: Clinical manifestations. Mov Disord, 11:11-6.

Jankovic J. 2008a. Parkinson's disease: clinical features and diagnosis. J Neurol Neurosurg Psychiatry, 79:368-76.

Jankovic J. 2008b. Are adenosine antagonists, such as istradefylline, caffeine, and chocolate, useful in the treatment of Parkinson's disease? Ann Neurol, 63:267-9.

Jankovic J. Stacy M. 2007. Medical management of levodopa-associate motor complications in patients with Parkinson's disease. CNS Drugs, 21:677-92.

Jouvent R, Abensour P, Bonner AM, et al. 1983. Antiparkinsonian and antidepressant effects of high doses of bromocriptine. An independent comparison. $J$ Affect Disord, 5:141-5.

Kompoliti K, Wang QE, Goetz CG, et al. 2000. Effects of central dopaminergic stimulation by apomorphine on speech in Parkinson's disease. Neurology, 54:458-62.

Korczyn AD, Brunt ER, Larsen JP, et al. 1999. A 3-year randomized trial of ropinirole and bromocriptine in early Parkinson's disease. Neurology, 53:364-70.

Korczyn AD, Thalamas C, Adler CH. 2002. Dosing with ropinirole in a clinical setting. Acta Neurol Scand, 106:200-4.

Kordower JH, Herzog CD, Dass B, et al. 2006. Delivery of neurturin by AAV2 (CERE-120)-mediated gene transfer provides structural and functional neuroprotection and neurorestoration in MPTP-treated monkeys. Ann Neurol, 60:706-15.

Krack P, Batir A, Van Blercom N, et al. 2003. Five-year follow up of bilateral stimulation of the subthalamic nucleus in advanced Parkinson's disease. N Engl J Med, 349:1925-34.

Krauss JK, Jankovic J, Grossman RG, eds. 2001. Surgery for Movement Disorders, Philadelphia, PA: Lippincott Williams and Wilkins. p 1-449.

Kumar R, Lozano AM, Sime E, et al. 1999. Comparative effects of unilateral and bilateral subthalamic nucleus deep brain stimulation. Neurology, 53:561-6. 
Kurlan R. 2004. Disabling repetitive behaviors in Parkinson's disease. Mov Disord, 19:433-69.

Lang AE, Gill S, Patel NK, et al. 2006. Randomized controlled trial of intraputamenal glial cell line-derived neurotrophic factor infusion in Parkinson's disease. Ann Neurol, 59:459-66.

Le W-D, Jankovic J. 2001. Are dopamine agonists neuroprotective in Parkinson's disease? J Drugs and Aging, 18:389-96.

Lees AJ, Katzenschlager R, Head J, et al. 2001. Ten-year follow up of three different initial treatments in de-novo PD. A randomized trial. Neurology, 57:1687-94.

Lees AJ, Ratziu V, Tolosa E, et al. 2007. Safety and tolerability of adjunctive tolcapone treatment in patients with early Parkinson's disease. J Neurol Neurosurg Psychiatry, 78:944-8.

LeWitt PA, Lyons KE, Pahwa R; SP 650 Study Group. 2007. Advanced Parkinson disease treated with rotigotine transdermal system: PREFER Study. Neurology, 68:1262-7.

Linazasoro G, Van Blercom N, Lasa A. 2003. Unilateral subthalamic deep brain stimulation in advanced Parkinson's disease. Mov Disord, 18:713-6.

Luck GC, Brown RG. 2002. Apathy in Parkinson's disease. J Neurol Neurosurg Psychiatry, 73:636-42.

Lucking CB, Durr A, Bonifati V, et al. 2000. Association between early onset Parkinson's disease and mutations in the parkin gene. New Engl $J$ Med, 342:1560-67.

Luginger E, Wenning GK, Bösch S, et al. 2000. Beneficial effects of amantadine on dopa-induced dyskinesias in Parkinson's disease. Mov Disord, 15:873-8.

Mancini F, Tassorelli C, Martignoni E, et al. 2004. Long term evaluation of the effect of quetiapine on hallucinations, delusions and motor function in advanced Parkinson's disease. Clin Neuropharmacol, $27: 33-7$.

Manson AJ, Turner K, Lees AJ. 2002. Apomorphine monotherapy in the treatment of refractory motor complications of Parkinson's disease: Long-term follow up study of 64 patients. Mov Disord, 17:1235-41.

Marks WL, Verhagen Metman L, Starr P, et al. 2006. Neurturin gene transfer for Parkinson's disease: motor outcomes from the initial CERE-120 clinical trial. Mov Disord, 21:608.

Marras C, Lang AE. 2003. Measuring motor complications in clinical trials for early Parkinson's disease. J Neurol Neurosurg Psychiatry, 74:143-6.

Merims D, Balas M, Peretz C, et al. 2006. Rater-blinded, prospective comparison: quetiapine versus clozapine for Parkinson's disease psychosis. Clin Neuropharmacol, 29:331-7.

Miyasaki JM, Al Hassan K, Lang AE, et al. 2007. Punding prevalence in Parkinson's disease. Mov Disord, 22:1179-81.

Miyasaki JM, Shannon K, Voon V, et al. 2006. Practice parameter: evaluation and treatment of depression, psychosis, and dementia in Parkinson's disease (an evidence-based review). Report of the subcommittee of the American Academy of Neurology. Neurology, 66:996-1002.

Nakao N, Nakai T, Nakai K, et al. 1999. Ablation of the subthalamic nucleus supports the survival of nigral dopaminergic neurons after nigrostriatal lesions induced by the mitochondrial toxin 3-nitropropionic acid. Ann Neurol, 45:640-51.

Nutt JG, Burchiel KJ, Comella CL, et al. 2003. Randomized, double-blind trial of glial cell line-derived neurotrophic factor (GDNF) in PD. Neurology, 60:69-73.

Nutt JG, Carter JH. 2000. Apomorphine can sustain the long-duration response to L-DOPA in fluctuating PD. Neurology, 54:247-50.

Nutt JG. 2007. Continuous dopaminergic stimulation: Is it the answer to the motor complications of Levodopa? Mov Disord, 22:1-9.

Obeso JA, Rodriguez-Oroz MC, Rodriguez M, et al. 2000. Pathophysiology of the basal ganglia in Parkinson's disease. TINS, 23:8-19.

Olanow CW, Tasmar Advisory Panel. 2000. Tolcapone and hepatotoxic effects. Arch Neurol, 57:263-67.

Ondo W, Hunter C, Almaguer M, et al. 1999. Efficacy and tolerability of a novel sublingual apomorphine preparation in patients with fluctuating Parkinson's disease. Clin Neuropharmacol, 22:1-4a.
Ondo W, Hunter C, Almaguer M, et al. 1999. Sublingual apomorphine in patients with fluctuating Parkinson's disease. Mov Disord, 14:664-8b.

Ondo W, Jankovic J, Schwartz K, et al. 1998. Unilateral thalamic deep brain stimulation for refractory essential tremor and Parkinson's disease tremor. Neurology, 51:1063-9.

Ondo WG, Fayle R, Atassi F, et al. 2005.Modafinil for daytime somnolence in Parkinson's disease: double blind, placebo controlled parallel trial. J Neurol Neurosurg Psychiatry, 76:1636-9b.

Ondo WG, Levy JK, Vuon KV, et al. 2002. Olanzapine treatment for dopaminergic-induced hallucinations. Mov Disord, 17:1031-5.

Ondo WG, Tintner R, Dat Voung K, et al. 2005. Double blind, placebo-controlled, unforced titration parallel trial of quetiapine for dopaminergic-induced hallucinations in Parkinson's disease. Mov Disord, 20:958-63a.

Ondo WG, Vuong KV, Khan H, et al. 2001. Daytime sleepiness and other sleep disorders in Parkinson's disease. Neurology, 57:1392-6.

Pact V, Giduz T. 1999. Mirtazapine treats resting tremor, essential tremor, and levodopa-induced dyskinesias. Neurology, 53:1154.

Pal PK, Calne DB, Calne S, et al. 1999. Botulinum-A toxin in the treatment of sialorrhea in patients with Parkinson's disease. Parkinsonism Relat Disord, 5:82.

Parkinson Study Group. 2002. Dopamine transporter brain imaging to assess the effects of pramipexole vs levodopa on Parkinson disease progression. JAMA, 287:1653-61.

Parkinson Study Group. 2003. A controlled trial of rotigotine monotherapy in early Parkinson's disease. Arch Neurol, 60:1721-8.

Parkinson Study Group. 2005. A randomized placebo-controlled trial of rasagiline in levodopa-treated patients with Parkinson disease and motor fluctuations: the PRESTO study. Arch Neurol, 62:241-8.

Pereira da Silva-Junior F, Braga-Neto P, Sueli Monte F, et al. 2005. Amantadine reduces the duration of levodopa-induced dyskinesia: A randomized, double-blind, placebo-controlled study. Parkinsonism Relat Disord, 11:449-52.

Pietz K, Hagell P, Odin P. 1998. Subcutaneous apomorphine in late stage Parkinson's disease: a long term follow up. J Neurol Neurosurg Psychiatry, 65:709-16.

Pillon B, Ardouin C, Damier P, et al. 2000. Neuropsychological changes between "off" and "on" STN or GPi stimulation in Parkinson's disease. Neurology, 55:411-8.

Poewe W, Leussi F. 2005. Clinical studies with transdermal rotigotine in early Parkinson's disease. Neurology, 65:11-4.

Poewe W, Wenning GK. 2000. Apomorphine: An underutilized therapy for Parkinson's disease. Mov Disord, 15:789-94.

Rabey JM, Prokhorov T, Miniovitz A, et al. 2007. Effect of quetiapine in psychotic Parkinson's disease patients: a double-blind labeled study of 3 months' duration. Mov Disord, 22:313-8.

Rajput AH, Fenton ME, Birdi S, et al. 2002. Clinical pathological study of levodopa complications. Mov Disord, 17:289-96.

Rascol O, Brooks DJ, Korczyn AD, et al. 2000. A five-year study of the incidence of dyskinesia in patients with early Parkinson's disease who were treated with ropinirole or levodopa. 056 Study Group. $N$ Engl $J$ Med, 18:1484-91.

Rascol O, Brooks DJ, Melamed E, et al; LARGO study group. 2005. Rasagiline as an adjunct to levodopa in patients with Parkinson's disease and motor fluctuations (LARGO, Lasting effect in Adjunct therapy with Rasagiline Given Once daily, study): a randomised, double-blind, parallel-group trial. Lancet, 365:947-54.

Ravina B, Camicioli R, Como PG, et al. 2007. The impact of depressive symptoms in early Parkinson's disease. Neurology, 69:342-7.

Reading PJ, Luce AK, McKeith IJ, et al. 2001. Rivastigmine in the treatment of parkinsonian psychosis and cognitive impairment: preliminary findings from an open trial. Mov Disord, 16:1171-95.

Reisberg B, Doody R, Stoffler A, et al; Memantine Study Group. 2003. Memantine in moderate-to-severe Alzheimer's disease. $N$ Engl J Med, 348:1333-41.

Rektorova I, Rektor I, Bares M, et al. 2003 Pramipexole and pergolide in the treatment of depression in Parkinson's disease: a national multicentre perspective randomized study. Eur J Neurol, 10:399-406. 
Reyner LA, Horne JA. 1998. Falling asleep whilst driving: are drivers aware of prior sleepiness? Int J Legal Med, 111:120-3.

Rich SS, Friedman JH, Ott BR. 1995. Risperidone versus clozapine in the treatment of psychosis in six patients with Parkinson's disease and other akinetic-rigid syndromes. J Clin Psychiatry, 56:556-9.

Richard IH. 2005. Anxiety disorders in Parkinson's disease. Adv Neurol, 96:42-55.

Rodriguez-Oroz MC, Obeso JA, Lang AE, et al. 2005. Bilateral deep brain stimulation in Parkinson's disease: a multicentre study with 4 years follow up. Brain, 128:2240-9.

Roth BL. 2007. Drugs and valvular heart disease. $N$ Engl J Med, 356:6-9.

Ruottinen HM, Rinne UK. 1998. COMT inhibition in the treatment of Parkinson's disease. J Neurol, 245:25-34.

Saint-Cyr JA, Trepanier LL, Kumar R. et al. 2000. Neuropsychologic consequences of chronic bilateral stimulation of the STN in Parkinson's disease. Brain, 123:2091-108.

Schapira AH, Olanow CW. 2004. Neuroprotection in Parkinson's Disease: mysteries, myths and misconceptions. JAMA, 291:358-64.

Schrag A, Schott JM. 2006. Epidemiological, clinical and genetic characteristics of early-onset parkinsonism. Lancet Neurol, 5:355-63.

Schrag A. 2005. Entacapone in the treatment of Parkinson's disease. Lancet Neurol, 4:366-70.

Schrag AS, Quinn N. 2000. Dyskinesias and motor fluctuations in Parkinson's disease. A community-based study. Brain, 123:2297-305.

Schuurman PR, Bosch A, Bossuyt PMM, et al. 2000. A comparison of continuous thalamic stimulation and thalamotomy for suppression of severe tremor. N Engl J Med, 342:461-8.

Shiba M, Bower JH, Maragnore DM, et al. 2000. Anxiety disorders and depressive disorders preceding Parkinson's disease: a case-control study. Mov Disord, 15:669-77.

Shoulson I, Oakes D, Fahn S, et al. 2002. Impact of sustained deprenyl (selegiline) in levodopa-treated Parkinson's disease: A randomized placebo-controlled extension of the deprenyl and tocopherol antioxidative therapy of parkinsonism trial. Ann Neurol, 51:604-12.

Shults CW, Oakes D, Kieburtz K, et al. 2002. Effects of coenzyme q10 in early Parkinson disease: evidence of slowing of the functional decline. Arch Neurol, 59:1541-50.

Simpkins N, Jankovic J. 2003. Neuroprotection in Parkinson's disease. Arch Int Med, 163:1650-4.

Starkstein SE, Mayberg HS, Preziosi TJ, et al. 1992. Reliability, validity, and clinical correlates of apathy in Parkinson's disease. J Neuropsychiatry Clin Neurosci, 4:134-9.

Stein MB, Heuser IJ, Juncos JL, et al. 1990. Anxiety disorders in patients with Parkinson's disease. Am J Psychiatry, 147:217-20.

Stern MB, Marek KL, Friedman J, et al. 2004. Double-blind, randomized, controlled trial of rasagiline as monotherapy in early Parkinson's disease patients. Mov Disord, 19:916-23.

Stern MB. 2004. Dopamine agonists modify the course of Parkinson disease. Arch Neurol, 61:1969-71.

Stocchi F, Vacca L, Berardelli A, et al. 2003. Dual dopamine agonist treatment in Parkinson's disease. J Neurol, 250:822-6.

Stocchi F, Vacca L, Ruggieri S, et al. 2005. Intermittent vs continuous levodopa administration in patients with advanced Parkinson disease: a clinical and pharmacokinetic study. Arch Neurol, 62:905-10.

Stover NP, Bakay RA, Subramanian T, et al. 2005. Intrastriatal implantation of human retinal pigment epithelial cells attached to microcarriers in advanced Parkinson disease. Arch Neurol, 62:1833-7a.

Stover NP, Okun MS, Evatt ML, et al. 2005. Stimulation of the subthalamic nucleus in a patient with Parkinson disease and essential tremor. Arch Neurol, 62:141-3b.
Takeshita S, Kurisu K, Trop L, et al. 2005. Effect of subthalamic stimulation on mood state in Parkinson's disease: evaluation of previous facts and problems. Neurosurg Rev, 28:179-86.

Tan EK, Ondo W. 2000. Clinical characteristics of pramipexole-induced peripheral edema. Arch Neurol, 57:729-32.

Tandberg E, Larsen JP, Aarsland D, et al. 1996. The occurrence of depression in Parkinson's disease. A community-based study. Arch Neurol, 54:175-9.

Tintner R, Manian P, Gauthier P, et al. 2005. Pleuropulmonary fibrosis after long-term treatment with the dopamine agonist pergolide for Parkinson disease. Arch Neurol, 62:1290-5.

Vazquez A, Jimenez-Jimenez FJ, Garcia-Ruiz P, et al. 1993. "Panic attacks" in Parkinson's disease: a long-term complication of levodopa therapy. Acta Neurol Scand, 87:14-8.

Verhagen Metman L, Dotto PD, LePoole K, et al. 1999. Amantadine for levodopa-induced dyskinesias. A 1-year follow up study. Arch Neurol, 56:1383-6.

Verhagen Metman L, Konitsiotis S, Chase TN. 2000. Pathophysiology of motor response complications in Parkinson's disease: Hypotheses on the why, where, and what. Mov Disord, 15:3-8.

Voon V, Thomsen T, Miyasaki JM, et al. 2007. Factors associated with dopaminergic drug-related pathological gambling in Parkinson disease. Arch Neurol, 64:212-6.

Voon V. 2004. Repetition, repetition and repletion: compulsion and punding behaviors in Parkinson's disease. Mov Disord, 19:367-70.

Watts RL, Jankovic J, Waters C, et al. 2007. Randomized, blind, controlled trial of transdermal rotigotine in early Parkinson disease. Neurology, 68:272-6.

Watts RL, Raiser CD, Stover NP, et al. 2003. Stereotaxic intrastriatal implantation of human retinal pigment epithelial (hRPE) cells attached to gelatin microcarriers: a potential new cell therapy for Parkinson's disease. J Neural Transm Suppl, 65:215-27.

Weiner WJ, Factor SA, Jankovic J, et al. 2001. The long-term safety and efficacy of pramipexole in advanced Parkinson's disease. Parkinsonism Relat Disord, 7:115-20.

Weiner WJ. 2004. Initial treatment of Parkinson disease: levodopa or dopamine agonists. Arch Neurol, 61:1966-9.

Weintraub D, Stern WB. 2007. Intervening in the neuropsychiatric features of Parkinson's disease. Expert Rev Neurother, 7:699-710.

Whone AL, Watts RL, Stoessl AJ, et al. 2003. Slower progression of Parkinson's disease with ropinirole versus levodopa: The REAL-PET study. Ann Neurol, 54:93-101.

Wilkinson DG, Passmore AP, Bullock R, et al. 2002. A multinational, randomised, 12-week, comparative study of donepezil and rivastigmine in patients with mild to moderate Alzheimer's disease. Int J Clin Pract, 56:441-6.

Williams-Gray CH, Foltynie T, Lewis SJG, et al. 2006. Cognitive deficits and psychosis in Parkinson's disease: A review of Pathophysiology and therapeutic options. CNS Drugs, 20:477-505.

Wolozin B, Wang SW, Li NC, et al. 2007. Simvastatin is associated with a reduced incidence of dementia and Parkinson's disease. BMC Med, 19:5-20.

Zanettini R, Antonini A, Gatto G, et al. 2007. Valvular heart disease and the use of dopamine agonists for Parkinson's disease. New Eng J Med, 356:39-46.

Zesiewicz TA, Gold M, Chari G, et al. 1999. The occurrence of depression in Parkinson's disease. Arch Neurol, 53:175-9.

Zhang SM, Hernan MA, Chen H, et al. 2002. Intakes of vitamins E and C, carotenoids, vitamin supplements, and PD risk. Neurology, 59:1161-9.

Zou L, Jankovic J, Rowe DB, et al. 1999. Neuroprotection by pramipexole against dopamine- and levodopa-induced cytotoxicity. Life Sci, 64:1275-85. 
